\title{
Damping the Inrush Current for Current Transformer
}

\author{
Dr.Yousif Alyounus ${ }^{1}$, Omar Ghazal $^{2}$, Enaam Albanna $^{3}$, Nabeel Z Abdulnabi ${ }^{4}$ \\ \{doctor1969yousifyounes@gmail.com1, omargg@uomosul.edu.iq2, enaam.albanna@ntu.edi.iq3\} \\ Electrical Eng. Dept. Engineering College, Mosul University, Environmental Sciences \&Technology \\ College, Mosul University, Northern Technical University
}

\begin{abstract}
The inrush current is a highly asymmetric transient magnetizing current resulting from saturation of the core of the transformer caused by excessive growth of magnetic flux in one direction only. The suggested strategy to damp the inrush current is adding an inductor in parallel with the circuit breaker (C.B., which has a very low resistance when it is closed) at different values of the adding inductor to determine the suitable values of the inductor to damp the probable inrush current. This strategy differs from other strategies because the damping inductor is connected in parallel with the C.B. only at closing the C.B. for a few cycles, The damping inductor prevents the excessive growth for the flux in the core of the CT which lead to saturating the core of $\mathrm{CT}$ and then, prevents the excessive growth for the inrush current for specific situations of switching. Finally, the MATLAB program is used to simulate the suggesting strategy.
\end{abstract}

Keywords: Inrush current, Damping the inrush current, Mal operation of CT transformer.

\section{Introduction}

Magnetizing inrush current in the CT transformer results from any abrupt changes of the magnetizing voltage [1]. The voltage applied to the primary of the CT transformer according to the instant of the applied voltage may drive the flux to build up to a maximum theoretical value of twice the steady-state flux plus any residual flux [2].

The inrush currents So, there is a necessity to override the consequences of the inrush current.

A significant electrodynamic and thermal stresses on the CT transformer windings as a result of inrush current could impair the CT transformer life time, produce mechanical stress to the transformer and may cause protection system malfunction [3].

Generally, the magnitude and duration of the inrush current depend on:

- The energizing point of the applied voltage wave.

- The residual flux in the CT transformer core and its sign with respect to the first half-cycle of the steady-state alternating flux.

- The saturation or maximum flux density of the ferromagnetic material of the CT transformer core.

- The total impedance of the protection circuit through which the inrush current flows $[4,5]$. 


\section{Analysis of Inrush Current}

An analysis of the transient phenomena of the magnetizing inrush current under various conditions is necessary to understand the high amplitude of the inrush current and explain why the inrush current is generated when connecting the $\mathrm{CT}$ transformer to the mains, leading to overloads $[1,6]$.

The voltage induced across the winding according to Faraday's law is given as:

$$
\mathrm{e}=\mathrm{d} \varphi / \mathrm{dt}
$$

Where,

$\varphi$ : is the flux in the core [7].

$$
v(t)=E \cdot \sin \omega t=-N d \emptyset / d t
$$

Where,

E: peak of the applied voltage (volt),

$\omega:$ angular frequency $(\mathrm{rad} / \mathrm{sec})$,

t: time(sec),

$\mathrm{N}$ : number of turns $(\mathrm{T})$.

A graphical description of the voltage induced across the winding is illustrated in Figure $1[1]$. 


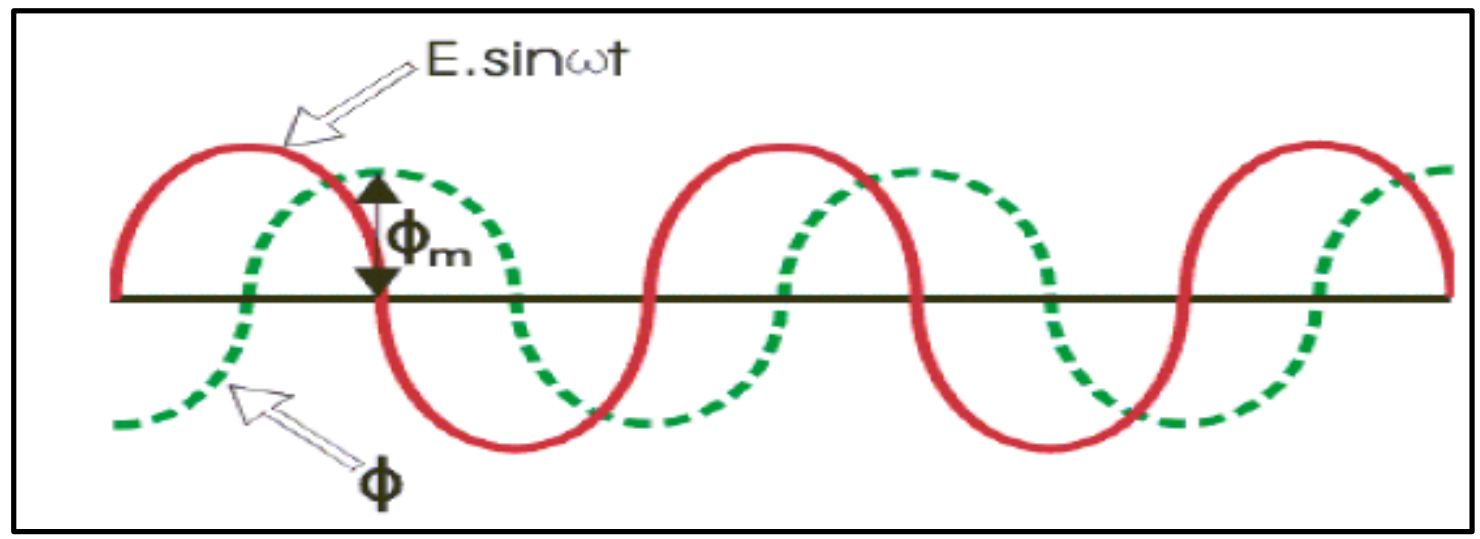

Fig. 1. The voltage induced across the winding and the initiated flux through the core of the CT transformer.

As shown from Figure 1 [1], the flux wave is initiated from the same origin as voltage waveform when the transformer is switched on at the instant of voltage equal to zero.

According to the above conditions, the value of flux at the end of the first half cycle of the voltage waveform will be twice, as shown in equation (3):

$$
\emptyset(t)=E / N \omega \int_{0}^{t} \sin \omega t . d(\omega t)=2 \varphi m
$$

Where,

$\varphi \mathrm{m}:$ is the maximum value of steady-state flux.

The transformer core is generally saturated just above the maximum steady-state value of flux.

The remanence flux in the core at the moment of switch on increases inrush current is illustrated in Figure 2 [2]. 


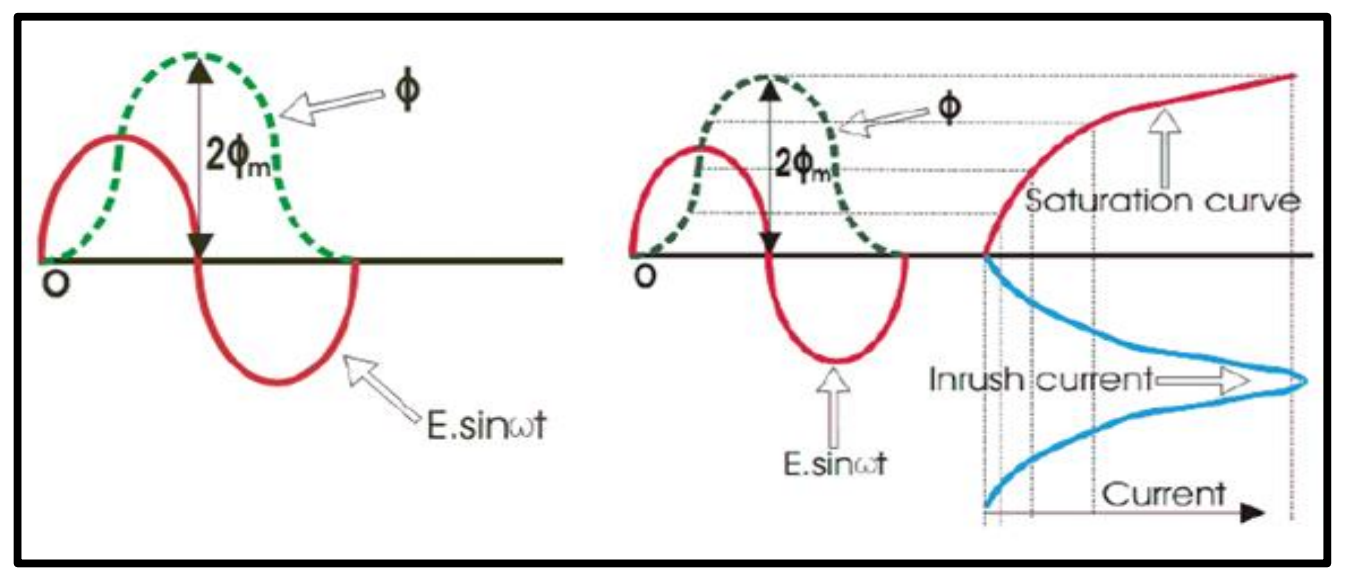

Fig. 2. Waveform showing the resulting inrush current from the saturated core of the CT transformer.

From the above figures and equations, the driving force of the inrush currents is the voltage applied to the primary of the transformer. This voltage forces the flux to build up to a maximum theoretical value of double the steady-state flux plus remanence $[8,9]$.

\section{The Suggested Strategy}

The suggested strategy interests of damping the inrush current. To investigate this suggestion, a suitable value of an inductor is connected in parallel with C.B. to damp the inrush current and saturation of CT.

For to investigate the assumed strategy. It is needed to find the relation between the adding inductor and the change in the flux.

As it is known, the self-induced emf may be determined from eq(4):

$$
e=-L \frac{d i}{d t}
$$

However, the induced emf is basically due to the rate of change of flux linkage. Thus, the emf may also be calculated by using equation (4), namely:

$$
e=-N \frac{d \emptyset}{d t}
$$


Since both equations [4] and [5] represent the same induced emf, then [4] must be equal to $[5]$.

Thus

$$
\frac{L d i}{d t}=\frac{N d \emptyset}{d t}
$$

The minus signs cancel out.[10]

So,

$$
L=\frac{N d \emptyset}{d i}
$$

Where, from the eq.(7) the change in flux decreased when the value of the inductor is decreased and then, there is a chance to damp the inrush current and switching the transformer be in a safe situation[9].

\section{Simulation and Results}

The simulation of studying the strategy of damping the inrush current is divided into two cases.

The first case dealt with the switching of CT at different times to discriminate against the instants at which the CT is saturated and prove the above analysis in the previous paragraphs.

The second case dealt with the treatment of saturation of CT with different values of inductor which is connected in parallel with C.B. to determine the suitable range of values of inductor which is necessary to damp the inrush current and saturation of CT.

\subsection{The first case}

For the tested model shown in Figure 3. [3], the switching of CT at different times of the applied voltage to discriminate the instants of the applied voltage at which the CT is saturated before adding an inductor to damp the inrush current. 


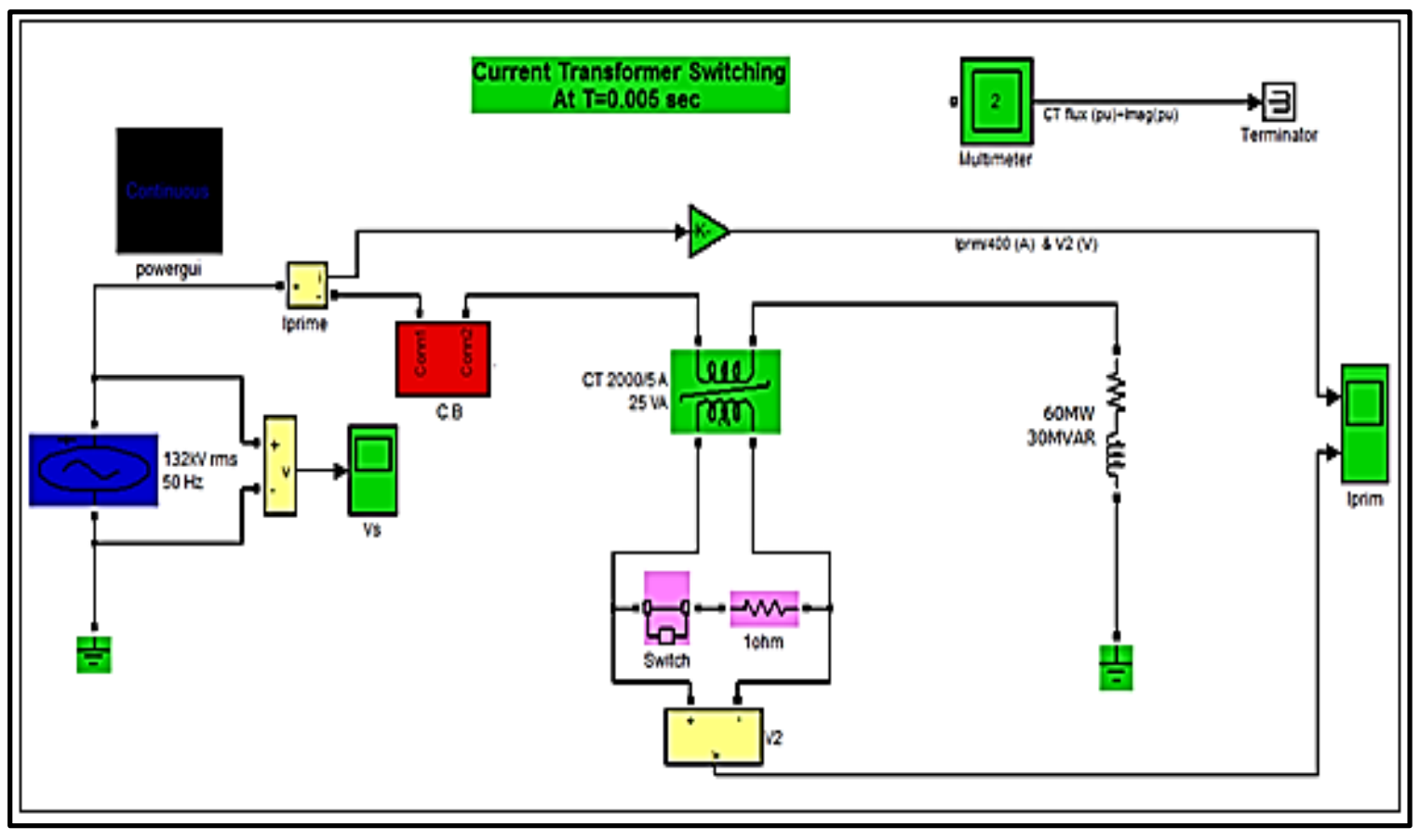

Fig. 3 The tested model.

The power frequency of the tested model is $50 \mathrm{~Hz}$ and then the period of each cycle is 0.02 sec, and the studied states are:

a. CT unsaturation: Start the simulation by closing the C.B. at $t=0.005 \mathrm{sec}$, and observe the magnetising current and flux.

As expected according to Figure 4. [4], the magnetising current and flux are sinusoidal. Each of flux and magnetising current contains a DC component which stays ineffective value. This switching produces no current asymmetry and the CT doesn't saturated. 


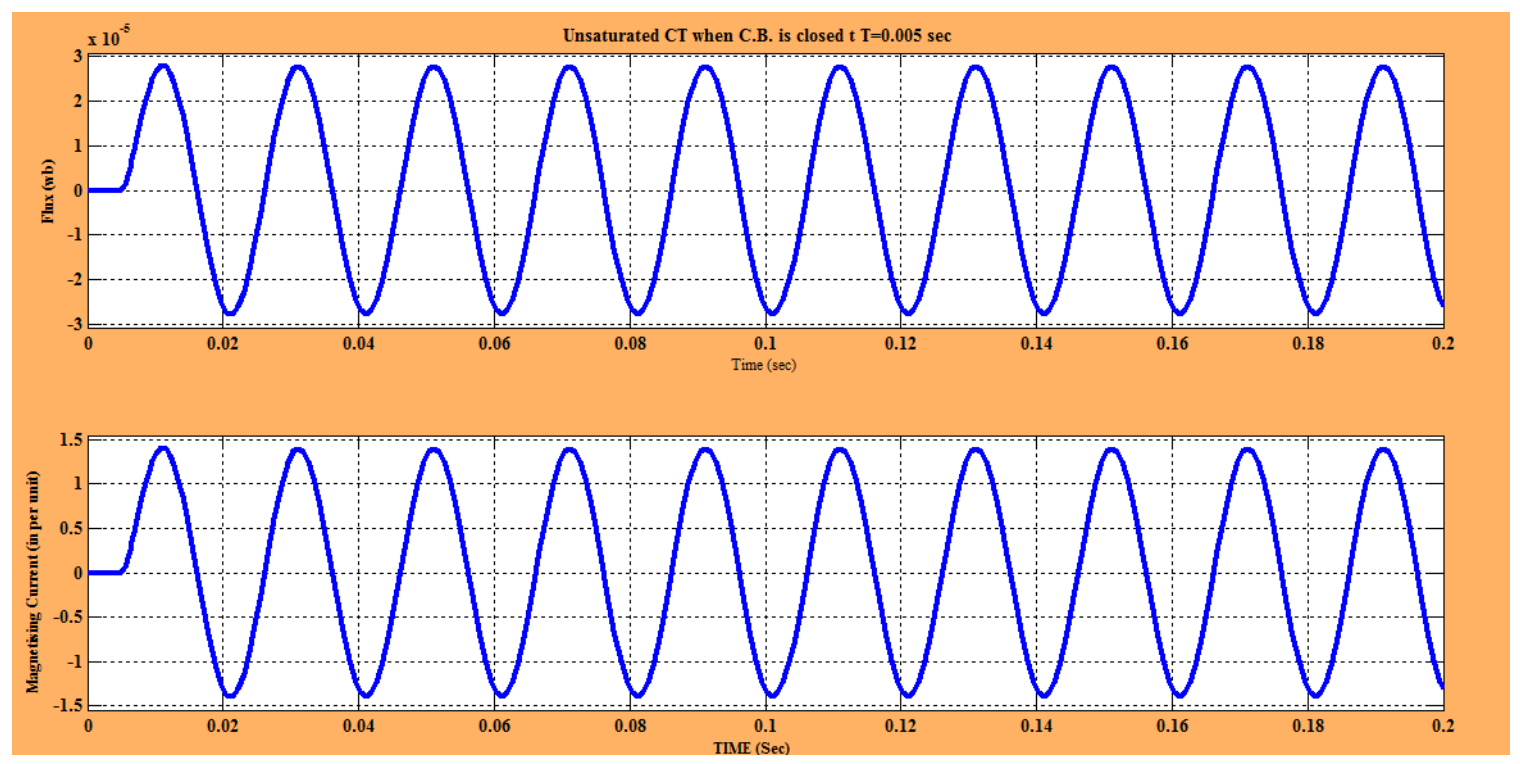

Fig. 4 Flux and Magnetising Current for CT Transformer when C.B. is closed at $\mathrm{t}=0.005 \mathrm{sec}$.

b. b. CT saturation: Start the simulation by closing the C.B. at $\mathrm{t}=0.0 \mathrm{sec}$, and observe the magnetising current and flux.

As expected and according to Figure 5. [5], the magnetising current and flux are sinusoidal. Each of flux and magnetising current contains a DC component which is an effective value. This switching produces current asymmetry and the CT is saturated because each of flux and magnetising current becomes twice the previous value. 


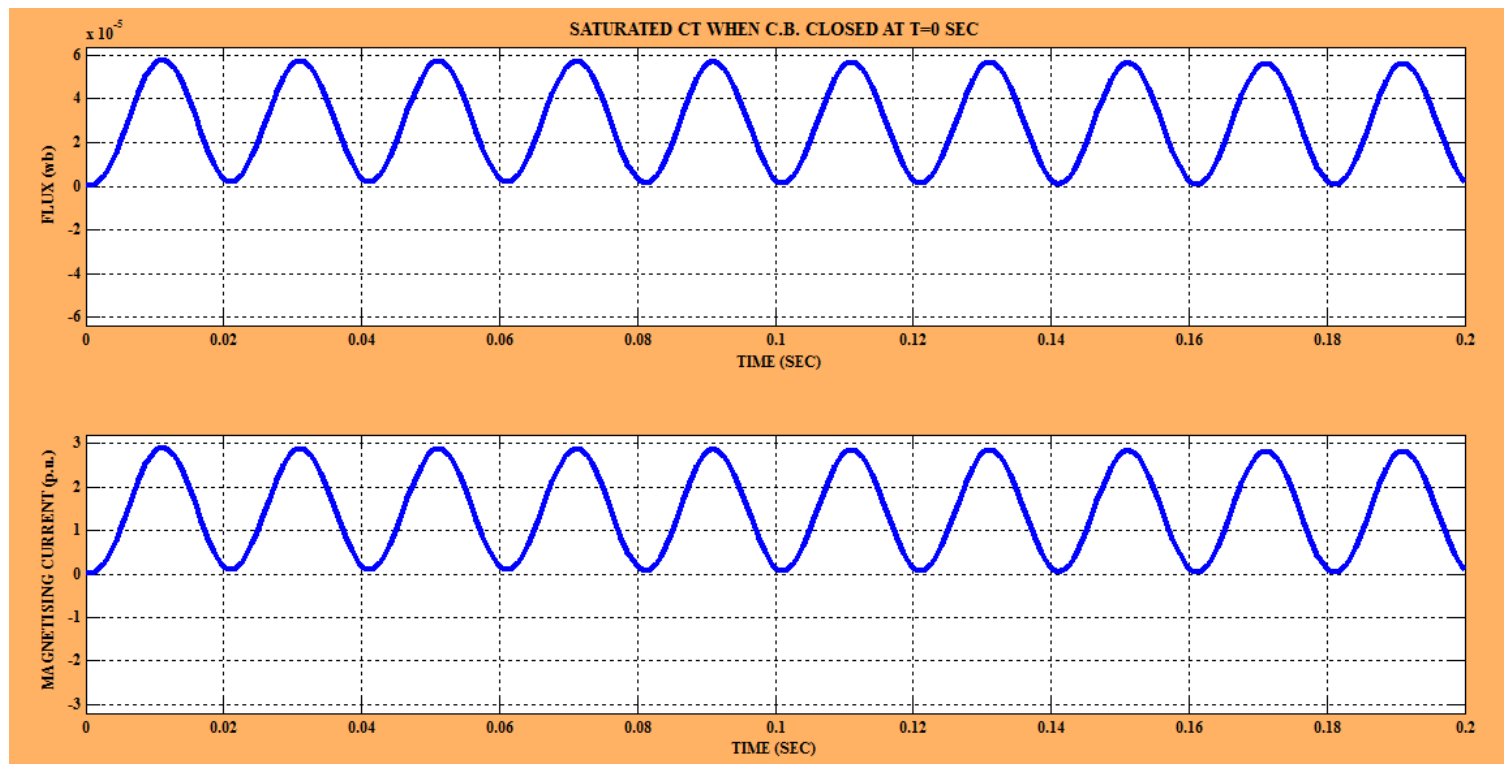

Fig. 5 Flux and Magnetising Current for CT Transformer when C.B. is closed at $\mathrm{t}=0.00 \mathrm{sec}$.

Here, the flux changes from zero to twice of a maximum flux then this value will causes a huge magnetizing inrush in the primary current.

\subsection{The second case}

Adding different values of an inductor to damp the inrush current and CT saturation

To avoid the consequences of the inrush current and saturation of current transformer, an inductor is connected in parallel with the breaker resistance.

\section{a. First state at different values of $\mathrm{L}(\mathbf{0 . 0 0 0 1 , 0 . 0 0 1 , 0 . 0 1 H )}$}

According to Figure [6],[7],[8] the CT doesn't saturated. 


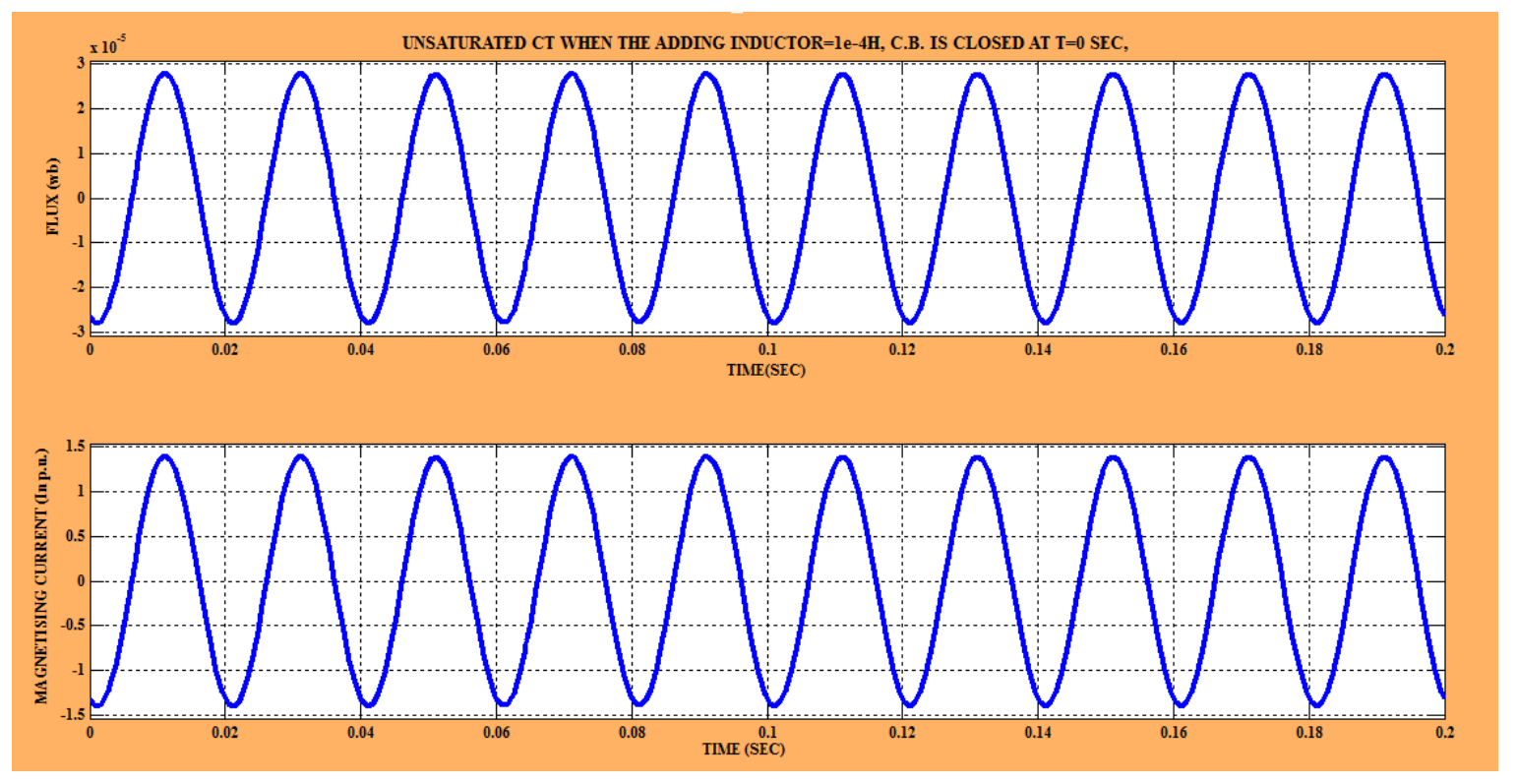

Fig. 6 Flux and Magnetising Current for CT Transformer when C.B. is closed at $\mathrm{t}=0.00 \mathrm{sec}$ and $\mathrm{L}=0.0001 \mathrm{H}$.
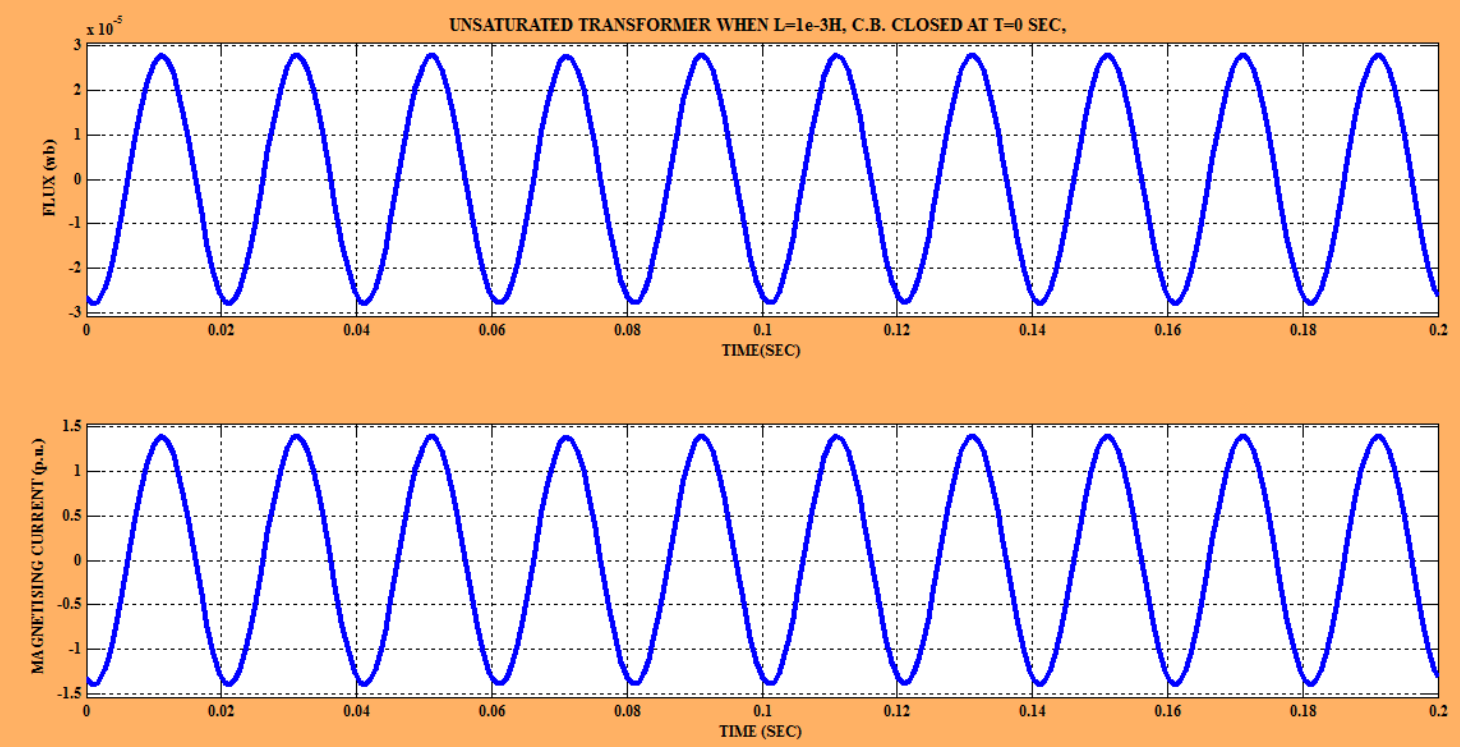
Fig. 7 Flux and Magnetising Current for CT Transformer when C.B. is closed at $\mathrm{t}=0.00 \mathrm{sec}$ and $\mathrm{L}=0.001 \mathrm{H}$.

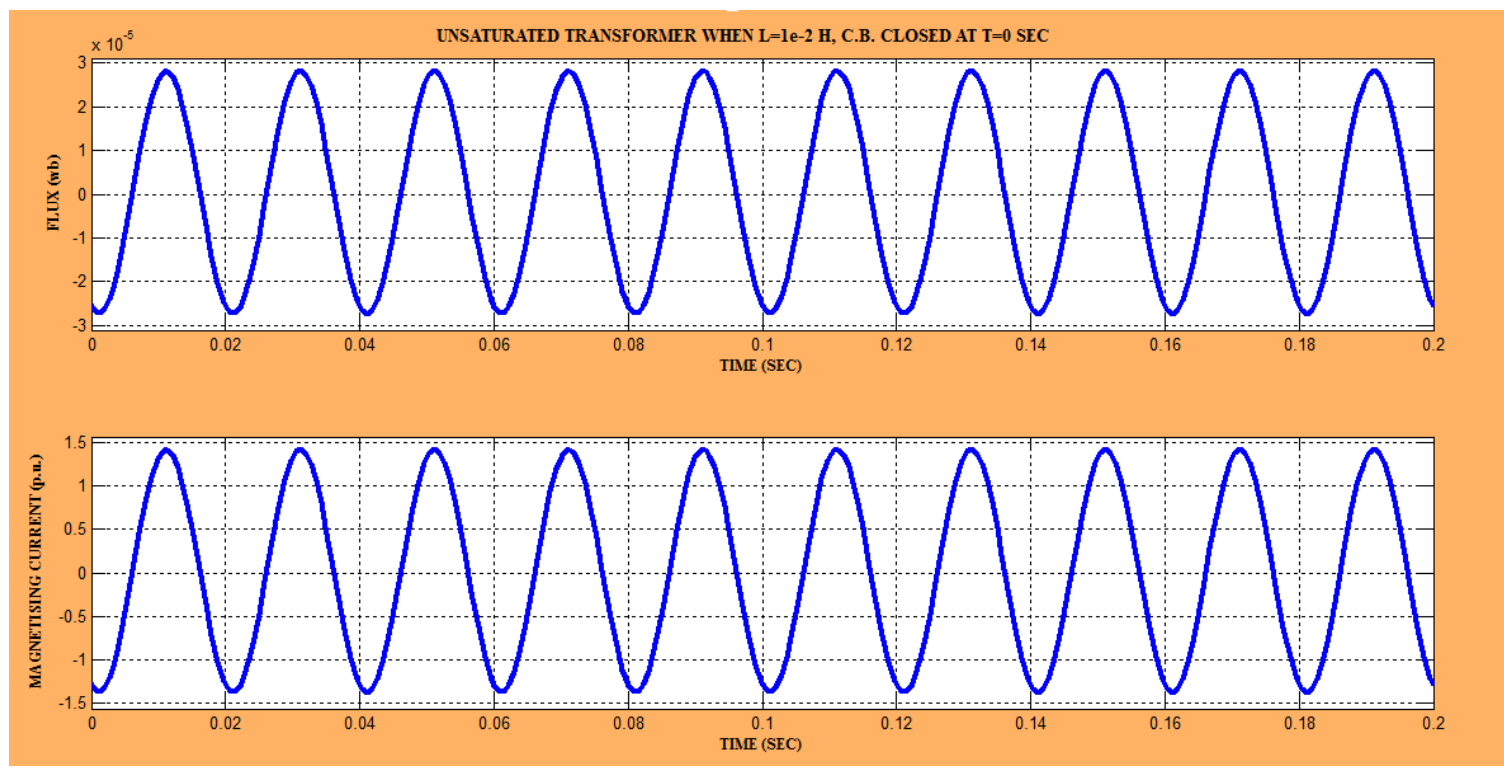

Fig. 8 Flux and Magnetising Current for CT Transformer when C.B. is closed at $t=0.00 \mathrm{sec}$ and

$$
\mathrm{L}=0.01 \mathrm{H} \text {. }
$$

b. Second state at different values of $\mathrm{L}(0.1,1.2 \mathrm{H})$

According to figures $(9$ and 10$)$, the CT is saturated when $(\mathrm{L}>=0.1 \mathrm{H})$ and the strategy is failed when the value of the inductor $>=0.1 \mathrm{H}$. 


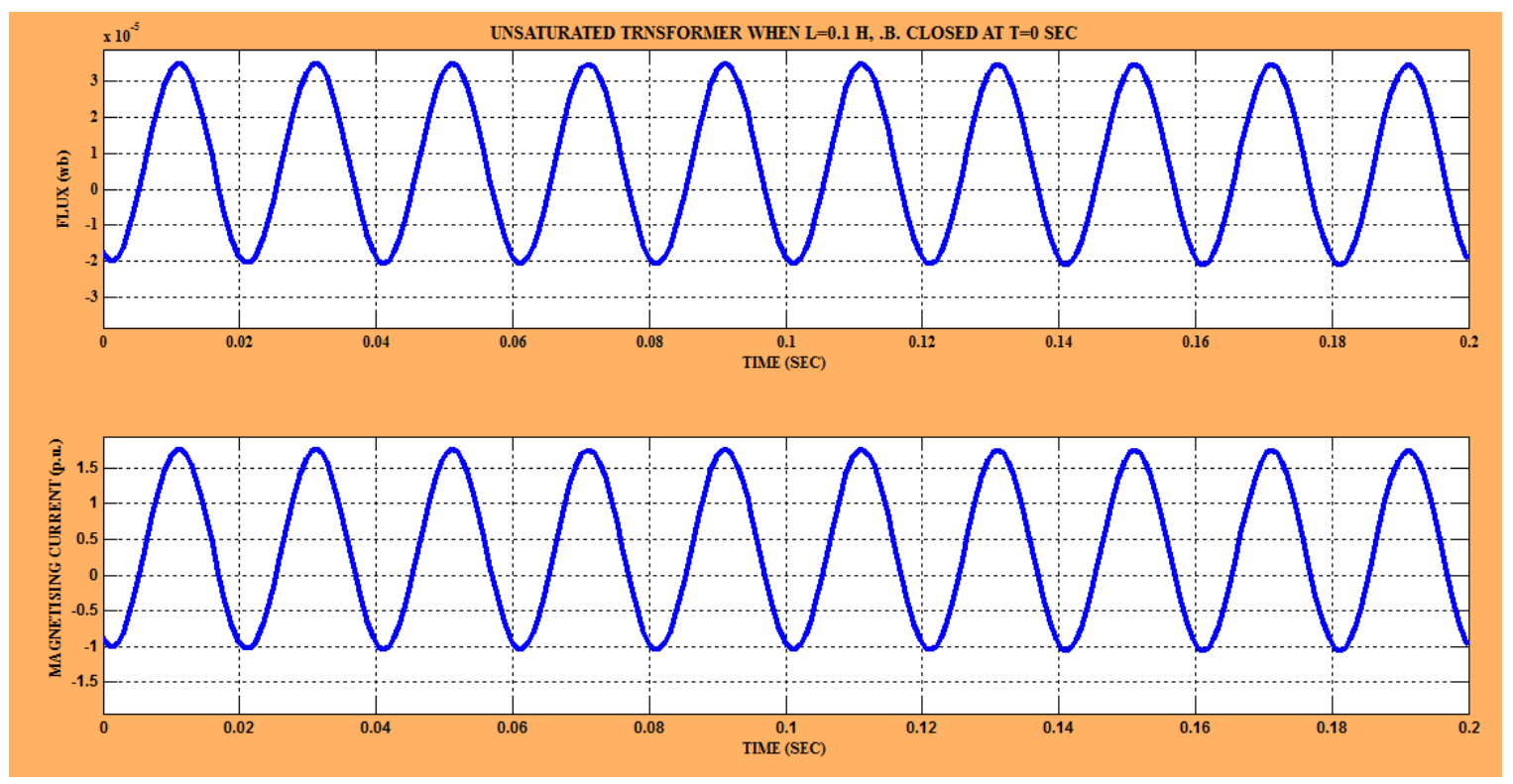

Fig. 9 Flux and Magnetising Current for CT Transformer when C.B. is closed at $\mathrm{t}=0.00 \mathrm{sec}$ and $\mathrm{L}=0.1 \mathrm{H}$.

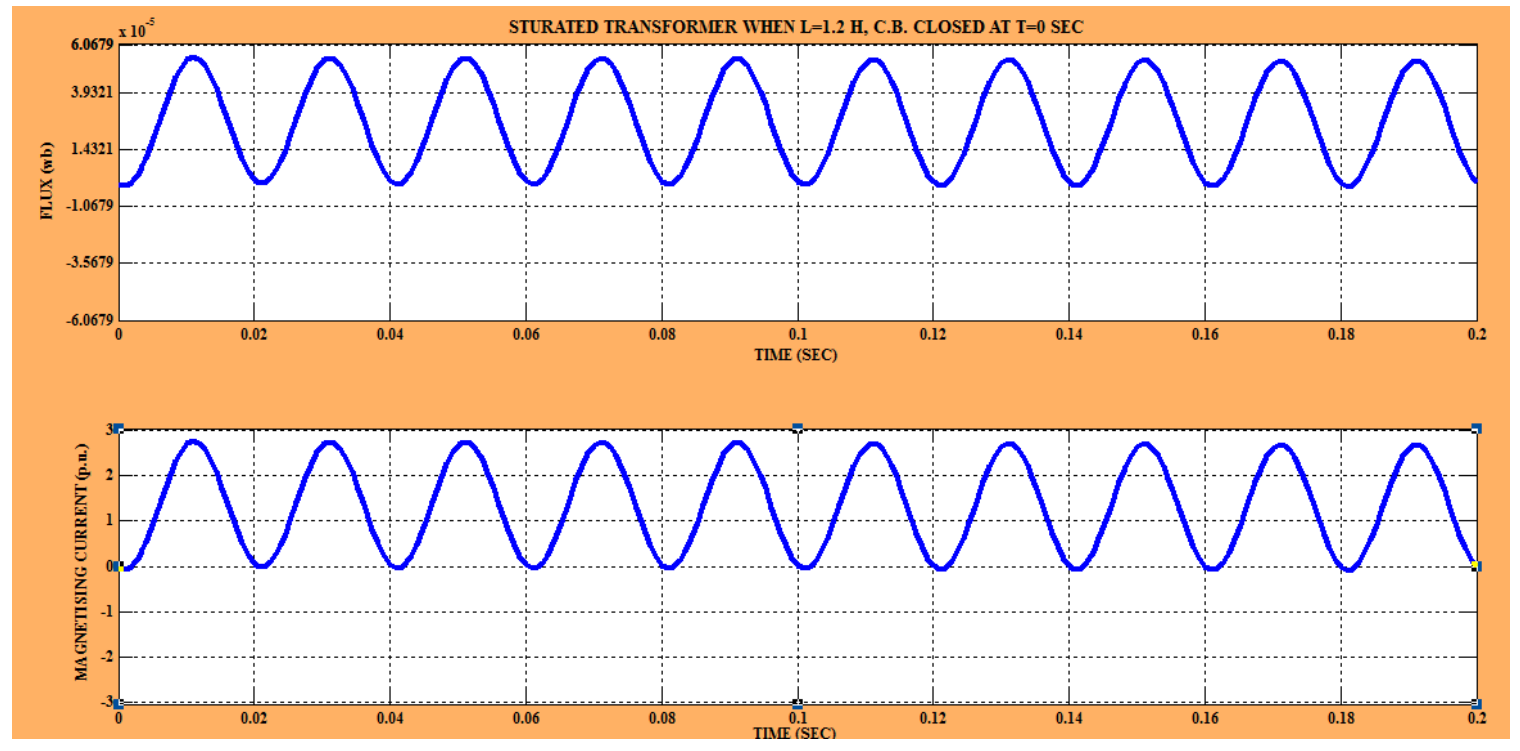


Fig. 10 Flux and Magnetising Current for CT Transformer when C.B. is closed at $\mathrm{t}=0.00 \mathrm{sec}$ and $\mathrm{L}=0.1 \mathrm{H}$.

From Figure 9. [9], the flux began in increase and the flux approach to twice of its value when the adding inductor equal to $1.2 \mathrm{H}$ as shown in Figure 10. [10]

These results approved the equation (7), so it is needed to small values of the adding inductor to damp the inrush current.

\section{CONCLUSIONS}

There are different strategies to reduce the inrush currents have been developed. These strategies like inserting current limiting elements such as resistors or reactors in series to the transformer windings, or, by inserting a voltage source inverter (VSI) controlled as a dynamic resistor in series or in shunt or by core flux manipulation.

But in this paper, a new strategy is used to damp not to reduce the inrush current by connecting an inductor in parallel with the breaker resistance. This strategy enhances the damping of the inrush current problem.

Also, according to the equation (7), the small value of the inductance prevent the rapid growth of the flux, and then avoiding the saturation of current transformer by damping the inrush current.

It is concluded that the main features of the used strategy in this current paper that it is simple and effective strategy to damp not to reduce the inrush current, unlike the previous methods.

\section{References}

[1] M. Jamali, M. Mirzaie: S. Asghar Gholamian, "Calculation and Analysis of Transformer Inrush Current Based on Parameters of Transformer and Operating Conditions", Electronics and Electrical Engineering, ISSN 1392 - 1215, 2011. No. 3(109).

[2] venkatesh Dugyala, ch.Nagalaxmi, v.K.R.Mohan Rao, "A Novel Control Strategy to Reduce Transformer Inrush Currents by Series Voltage Sag Compensator", International Journal of Engineering Research and Development, Volume 8, Issue 5 (August 2013), PP. 54-63.

[3] R. S. Girgis, E. G. teyenhuis, "Characteristics of Inrush Current of Present Designs of Power Transformers", Proceeding of the IEEE Power Engineering Society General Meeting, 24-28 June 2007, pp. 1-6.4. 
[4] Andrzej Dobrogowski, Przemyslaw Lisowski, "The Dependence of the inrush current of a transformer upon switching off/on phases", XIX IMEKO World Congress Fundamental and Applied Metrology, September 6-11, 2009, Lisbon, Portugal.

[5] J. Burkard and J. Biela, "Transformer Inrush Current Mitigation Concept for Hybrid Transformers", Laboratory for High Power Electronic Systems (HPE), ETH Zurich, Physikstrasse 3, CH-8092 Zurich, EPE'17 ECCE Europe ISBN: 9789075815276 et CFP17850ART P.4.

[6] Maria-Cristina Nițu, Claudiu-Ionel Nicola*, Marcel Nicola, Marian Duță, "Determination of Inrush Current to High Power Transformers using the LabVIEW Environment", Journal of Mechanical Engineering and Automation 2017, 2-7-2017.

[7] Reena Moon, R.K.Dhatrak, "A Study of Effect of Magnetizing Inrush Current on Different Ratings Of Transformers", International Journal of Advanced Research in Electrical, Electronics and Instrumentation Engineering (An ISO 3297: 2007 Certified Organization) Vol. 3, Issue 4, April 2014.

[8] P6.(P6)Mr. Pradeep J. Kotak Prof. Alka Thakur, "Inrush current reduction in three phase transformer by using prefluxing technique ", International Journal of electrical engineering \& technology (IJEET), Volume 5, Issue 10, October (2014), pp. 23-32.

[9] Brian Gladstone, "Solving Inrush at the Source" Power Electronics Technology, Plitron Manufacturing Inc., Toronto, Canada,April 2004.

[10] Christopher R Robertson, "Fundamental Electrical and Electronic Principles", Third Edition, Third edition 2008, ISBN: 978-0-7506-8737-9Copyright () 2008 Elsevier Ltd.

[1] MATLAB and Simulink 7.10, The Math Works, Copyright 1997-2006, Inc. 